Vol. 10(45), pp. 967-977, 8 December, 2016

DOI: 10.5897/AJPP2016.4652

Article Number: 44132BD62005

ISSN 1996-0816

Copyright (C) 2016

Author(s) retain the copyright of this article

http://www.academicjournals.org/AJPP

African Journal of Pharmacy and Pharmacology

\title{
Progress test: A review to motivate their use in pharmacy schools in Brazil
}

\author{
Alberto Malta Junior ${ }^{1 *}$, José Lucio Martins Machado ${ }^{2}$, Maria Jutta Shadeck ${ }^{3}$, Anabel Fonseca \\ Ferrari $^{3}$ and Carlos Fernando Collares ${ }^{4}$
${ }^{1}$ Pharmacy School, Faculty of Juazeiro do Norte, Ceara, Brazil. Student of the Master Program in Management of Technology and Innovation in Health of the Hospital Sírio Libanês, São Paulo, São Paulo, Brazil.
${ }^{2}$ Botucatu Medical School, Universidade Estadual Paulista - UNESP, Brazil.
${ }^{3}$ Undergraduate Medical Student of Universidade Municipal de São Caetano do Sul, Brazil.
${ }^{4}$ Department of Educational Development and Research, Maastricht University, Maastricht, The Netherlands.

Received 15 August 2016, Accepted 22 November, 2016

\begin{abstract}
Progress Test (PrT) is a longitudinal assessment strategy in which tests composed of contents from all the curriculum are periodically applied to all students of a course. Such strategy allows measurement of deep, long-lasting meaningful learning as well as early detection and remediation of underperforming students. It was introduced more than forty years ago, and it has been used in several health schools in the world, especially medicine. Assessment of students' knowledge gain and its application over the course is a challenge. PrT has become a relevant method to monitor the development of the student through graduation. There is no culture of using longitudinal assessments in Brazil's pharmacyschools. This scenario is an opportunity for use of PrT. The objective of this work is to make a literature review about how progress test has been used in context of education. The authors also discuss the possibilities of PrT's application in Pharmacy undergraduate courses in Brazil. PrT has a long history of use by various institutions in the world. Most user experiences come from medical schools, but there are articles showing the application of PrT in dentistry and psychology schools. PrT has been shown to be an effective assessment tool in a problem-based (PBL) and traditional curricula. PrT is recommended as a tool to longitudinal assesses growth in knowledge. Phamacy schools may develop their own framework for PrT collaborations, which could optimize the educational utility of student's assessment instruments as tools to enhance learning.
\end{abstract}

Key words: Progress test, assessment, knowledge.

\section{INTRODUCTION}

The Progress Test $(\operatorname{PrT})$ is a longitudinal assessment strategy in which tests composed of contents from all the curriculum are periodically applied to all students of a course, with the expectancy that a progressive proportion of answers will be right (Vantini and Benini, 2008). Such strategy allows measurement of deep, long-lasting

*Corresponding author. E-mail: farmacia@fjn.edu.br. Tel: +55 88 2101-2777.

Author(s) agree that this article remain permanently open access under the terms of the Creative Commons Attribution License 4.0 International License 
meaningful learning as well as early detection of underperforming students. Information obtained from progress testing results also serve as a quality assurance tool for institutional stakeholders to help prioritize efforts on curricular governance and faculty development (Verhoeven et al., 2002). It has been introduced more than forty years ago, and it has been practiced in various health schools in the world, especially medicine (Vleuten et al., 1996; Verhoeven et al., 1999; Finucane et al., 2010; Freeman et al., 2010; Bennett et al., 2010). PrT was developed in the context of problem based learning (PBL), but its use was not restricted to PBL programmes (van der Vleuten et al., 2004; Verhoeven et al., 2005). The PrT values the knowledge acquired during the period of graduation, not individual curricula (Nouns et al., 2012).

It is expected that the curriculum of the faculty can produce a solid knowledge to the student. A welldeveloped curriculum should ensure the development of cognitive, psychomotor and affective skills (Al Alwan et al., 2011). The Ministry of Education published in Brazil the pharmacy courses curriculum guidelines in 2002. This guide has been published to meet the training needed in the face of increased pharmacist insertion in health services, especially public health. It is intended that the final objectives of a curriculum must relate to the reality of where the pharmacist works, after all, the quality of pharmaceutical services depend on the quality of learning to preparing individuals for the several changes and challenges (Ogaji et al., 2016). In addition to this, the amount of pharmacy courses has multiplied and this fact demands capable assessment tools to qualify learning and harmonize the knowledge taught in institutions. Currently most of the pharmacy courses in Brazil adopt assessment methodology focused on tests at the end of each module. This use promotes the short-term memorisation or unrelated facts rather than promotes deep learning. PrT has become a relevant method to monitor the development of the student through graduation (Langer and Swanson, 2010; Al Alwan et al., 2011; Gold et al., 2015).

The central question who guided this review was: What contribution can the progress test give for learning to the schools of pharmacy in Brazil?

The aim of this work is to make a literature review about how progress test has been used used in context of education. The authors also discuss the possibilities of PrT's application in Pharmacy courses in Brazil.

\section{MATERIALS AND METHODS}

To accomplish this literature review, the authors used the SCOPUS $\AA$ database. It is one of the largest abstracts and citation database of peer-reviewed literature in the world. The keywords used for research in Scopus ${ }^{\circledR}$ were progress test delimited by inverted commas. This search was conducted in April of the year 2016.

In Scopus ${ }^{\circledR}$ database we select as inclusion criteria all the the original articles and reviews on the progress test in higher education; articles or reviews written in english or portuguese, published between 1990 and 2015; subject area included was only medicine, dentistry, social sciences, psychology and nursing. There were exclusion criteria: Notes, conference paper and book chapter. The search in database brought articles not relationed to progress test and was not considered to analysis. Some articles with terms "progress" or "test" isolated, appeared on search results and it was excluded as well.

\section{RESULTS}

The search finds 128 documents. After applied exclusion criteria, 65 articles were elegible to analysis. The main results are presented in Table 1 . To make it easier to understand, it were analyzed considering the following criteria:

1. PrT as assessment tool through graduation

2. PrT as assessment tool through post-graduation

3. Investigation about standards to PrT

4. Practices to application of PrT

5. PrT used in collaboration

6. PrT as instrument to comparison

\section{DISCUSSION}

The number of pharmacy schools in Brazil is growing. This scenario demands instruments to ensure that the pharmacist is being well formed. For any course of university education, it is important to monitor how it develops the cognition of students. It is argued that the assessment of this growth needs to mix formative assessment elements to improve performance, or summative, for accountability purposes and making decision (Schauber and Nouns, 2010). The relationship between an educational program and the method of evaluation is vital because the tests and examinations lead student learning (Verhoeven et al., 1999). The PrT is a real possibility to assess gain of knowledge by students. Besides that, for students who have submitted to a PrT there were more consistent and significant progress in academic's results when compared to students without it. That is because students tested continuously tend to retain knowledge more effectively (Schaap et al., 2012).

The set of articles present the evidence that PrT is a valuable method to assess and monitor the student's advancement (Boshuizen et al., 1997; Verhoeven et al., 2002; Dijcks et al., 2003; Rodrigues and Catarina, 2007; Löwe et al., 2008; De Champlain et al., 2010; Nouns et al., 2012; Al Alwan et al., 2011). Most studies describe experiences of the use of PrT in medical schools, but it is also used in other courses such as psychology, dentistry or nursing (Finucane et al., 2010; Norman et al., 2010; Muijtjens et al., 2008; Schaap et al., 2012; Ravesloot et al., 2012; Sangestani et al., 2013; Postma and White, 
Table 1. Main results of aplication of progress test.

Objective/Reference
PrT as assessment tool through graduation
To understand the influence of PrT in students' behaviour and
students' perceptions (Berkel et al., 1994)
To measure if there are differences in kinetics and acquisition of
knowledge among students from three countries (Albano et al.,
1996)

To describe the experience of the Personal Progress Index as a PrT at the McMaster University (Blake et al., 1996)

To evaluate the impact of PrT on the scores on a Clinical Reasoning Test (CRT). To investigate how PrT scores contributes to the CRT scores through the years (Boshuizen et al., 1997)

To evaluate the extension of study between academics of a medical school in first and later years (Hurk et al., 1999)

To study the progression of knowledge in students over the course in a medical school's problem-based curriculum through PT scores (Verhoeven et al., 2002).

To explore whether students are still gaining knowledge about basic sciences through the years (O'Neill, 2000)

To analyze relation to peer-rated competence of students with the relevance of written longitudinal tests, block tests and OSCEs (Dijcks et al., 2003)

To confront the consistency of different dimension of selfdirected clinical learning (Dornan et al., 2003)

To measure the quality of undergraduate education between medical students in psychiatry and behavioral sciences (van Diest $R$ et al., 2004).

To plan and administer a competence test throughout the Sheffield undergraduate medical course related to musculoskeletal system knowledge gain (Basu et al., 2004)

To implement the PrT as periodic evaluation; assess whether the knowledge gain has continuity; to check for loss of knowledge in the area of basic sciences at the end of the course (Tomic et al., 2005)

To analyze models of learning, training and progress evaluation (Vantini and Benini, 2008)

\section{Main results}

PrT support learning processes meaning oriented in contrast to repetition oriented learning. When both progress tests and block tests are summative used, PrT is not seen by students as an effective method to develop a meaningful learning

Perhaps Prt is not the most appropriate method for assessing students in international exchanges. Despite this, the authors consider that the PrT can be used to measure the gain of cognition in areas such as basic sciences.

PrT was well accepted by the students as a means of measuring growth of knowledge. The analysis of PPI scores allows us to identify students with learning problems.

PrT is a relevant instrument for monitoring the student's progression. It correlates with the CRT scores, specially in clinical sciences. Despite this, there are questions that depend on the school's aim and policy.

PrT was used as a parameter to evaluate the behavior of students relationed with dimension of learning.

PrT scores of 21 years reveal a growth in knowledge related to training time.

PrT was used for summative assessment of knowledge. The researchers observed an advancement in the basic Science scores evaluated by PrT

Progress test is a valuable tool to predict a profile of functioning student

There was no association between results on PrT with selfreported real patient learning instrument. Probably because PrT covers knowledge and seems less effective to this measure

Conclusions after application of PrT point a significant increase in knowledge growth for psychiatry and behavioral sciences. The measurements were made between the $1^{\text {st }}$ year and the end of the 6th year among academics

An adaptation of PrT was used to measure gain of knowledge. Authors found an adequate knowledge about musculoskeletal medicine between students after application of PrT

The authors showed that it was possible the implementation of PrT; there was progressive knowledge gain from first to last year in all tests; the knowledge related to basic sciences were kept

The authors summarize questions about learning, progression of the students, competence, responsibility, continuity and assessing progression. PrT is discussed as a method that assesses the comprehensive knowledge and its progression. 
Table 1. Cont'd.

To compare the level of knowledge of graduate students with a university degree with to the ones with college degree (CohenSchotanus et al., 2008).

To discuss the implementation of PrT in medical schools in Germany (Nouns and Georg, 2010)

To study long-term effect of PrT on student learning (Norman et al., 2010)

To evaluate the PrT as a predictive factor to identify behaviour of knowledge in medical students related to basic and clinical Science (Alwan et al., 2011)

To analyze perceptions and preparations by medical students for the PrT (Wade et al., 2012)

The objective of this study was characterized by the development of knowledge among first-year psychology students (Schaap et al., 2012)

To compare the performance among students in development and retention of knowledge in the basic medical sciences (Nouns et al., 2012)

To investigate relations between student characteristics and academic achievement (de Koning et al., 2012).

To report the innovative use of the National Board of Medical Examiners Comprehensive Basic Science Examination as a PrT throughout the preclerkship medical curriculum (Johnson et al., 2014)

The objective of this study was to evaluate the stress and student learning by comparing the PrT with traditional forms of assessment (Chen et al., 2015)

To make a literature review investigating the result of different learning environments. (Schauber et al., 2015).

To share the experience of building PrT in an undergraduate dental programme (Ali et al., 2015)
Analysis of results from a PrT revealed that there were no differences between the groups of evaluated students

PrT was proposed by students, who looked for meaningful learning in undergraduate education. The study showed that it is possible to compare knowledge between schools within a context of cooperation. The longitudinal application of PrT contributed to the understanding of formative assessment and improved the quality of examinations

The implementation of a formative PrT has a beneficial consequence for performance in a national licensing examination. The introduction of the PrT in an institution reduced failure rate by $3 / 4$

Results of PrT have showed that students performed better in clinical sciences than the basics'. In this experiment the results were used to modify the curriculum

Students elected three major factors around PrT: PrT's capacity to assess behavior of knowledge, to assist clinical learning and its importance for exam preparation

PrT scores showed that the growth of knowledge was different among the students. Nevertheless, due to some limitations, researchers receive this result with caution

PrT allows understanding the advance of knowledge in both traditional and PBL reformed medical curriculum.

Department of Psychology uses the PrT as a central method of assessment. Based on PrT results, authors concluded that three factors are strong predictors of academic development: students observed learning activities across the course, conquests in secondary education and during the first two bachelor years, as well as in their verbal abilities

This work demonstrated the use of the CBSE as a PrT has an important role as an evaluation method

A low sense of stress was achieved with the application of PrT. For the other hand this research found no evidence that PrT enhances learning.

PrT was used as indicator of academic achievement. This work showed that there was a better performance of students through the time, but PT was not able to detect application of knowledge.

PrT features: Being applied to students from all 4 years; also, realized twice a year; it is a formative assessment in years 1 and 2 and summative in subsequent years; each test adopts 100 single best answer multiple-choice items; among the options there is a 'don't know' option; it uses negative marking and 0 for 'don't know' answers. PrT has validity and reliability to assess growth in knowledge through the undergraduate program 
Table 1. Cont'd.

\section{PrT as assessment tool through post-graduation}

To evaluate extension of post-graduation training in general practice on the acquisition of knowledge of trainees (Kramer et al., 2003)

To investigate the behavior of the residents of anesthesia relating affective-motivational variables with study strategies (Rodrigues and Catarina, 2007)

To measure the effect of a 1-year resident training program in clinical research (Löwe et al., 2008)

To verify the validity and reliability of a national PrT in postgraduate Obstetrics and Gynecology training (Dijksterhuis et al., 2009)

To investigate the quality and validity of PrT in postgraduate radiology training (Ravesloot et al., 2012)
Application of PrT allowed showing that post-graduation training promotes an increase in knowledge between students. The gain of knowledge in a 3-year program is better than in a 2-year program

The growth of the knowledge of the basic sciences among residents of anesthesia was associated with anxiety related to the activities of study, results, motivation to study, the individual improvement and to the ability in choosing main ideas from subject matters

Use of the PrT shows growth on research knowledge

The results of this study were not satisfactory. The PrT has not presented validity and reliability

The study finds that PrT is a valuable method in medical specialty education. For the other hand, the study doesn't allow to relation visual skills with knowledge. Reliability and construct of validity were found by researchers

\section{Practice to application of PrT}

To review the application and some results of PrT after 15 years of experience (Vleuten et al., 1996)

To inspect methods which have been used to assess the outcomes of single tests, and to advice best practices (McHarg et al., 2005)

To evaluate the use of questions with short answers (Rademakers et al., 2005)

To describe a development of a web-based tool to give feedback to students (Muijtjens et al., 2010)

To discuss aspects of the development of the PrT (Ricketts et al., 2010).
PrT has a central role of PBL program. It magnifies the student-centered learning. Several universities in the Netherlands have been using the progress test. The domain of knowledge by students of Maastricht is equal to other institutions that do not have progress test. The multiple-choice questions are more reliable. Progress test was developed in the context of PBL, but it can be used in traditional educational programs

Authors recommend that the norm referencing is better than criterion referencing; number-right marking is less recommended than negative marking; discontinuous scale is better than a continuous scale.

The authors consider that to adopt short answer questions is relevant to formulate and implement PrT. The time and costs of question plan and marking the answers are acceptable. The process will be simplified with adoption of computerizing

The study showed that the Progress Test Feedback (PRoF) system was developed in two years, it was tested in several schools and it has many features. Although the authors consider the system useful for teachers and students, they understand that it takes more evidence to prove the integration of summative and formative assessment

This work raises questions about how best to apply the test. Two aspects are considered in the article: cost and reliability. The reliability increases with the size and the test frequency. On the other hand, discusses choose larger and less frequent testing as the best way forwards. This aspect can reduce the global costs for the test. However, the analysis did not link the issues of cost and reliability to educational impact and acceptability. 
Table 1. Cont'd.

To investigate if multiple choice tests are fair to students in medical schools with specific learning disabilities (Rickets et al., 2010b)

To evaluate whether a variant of PrT could recognize poor performing students (Kerfoot et al., 2011)

To evaluate acceptance of formative assessment comparing computer-based with paper-based assessment (Karay et al., 2012)

Investigation about standards to PrT

To investigate application of standards (relative or absolute) for approval or disapproval and check for a substantial increase of the variation in the failure rate per test (Muijtjens et al., 1998)

To investigate standards for the PrT (Verhoeven et al., 1999)

To describe the steps and approaches necessary to achieve effective peer review and to produce tests of consistent high quality (Verhoeven et al., 1999b)

To characterize the reliability and credibility of Angoff procedure and do a comparison of the standards (Verhoeven et al., 2002b)

To demonstrate a statistical method used in context of PT, called the cumulative deviation method and which is intended to elicit trends in longitudinal knowledge growth across the undergraduate curriculum and that can be used for benchmarking (Muijtjens et al., 2008)

To purpose a new standard setting for PrT (Ricketts et al., 2009).

To study the basis of equating in context of PrT (Langer and Swanson, 2010).

To discuss the use of blueprint to enable increasing and new opportunities for feedback in context of PrT (Coombes et al., 2010)
The authors analyzed a series of PrT questions applied to a group of students including those with some disabilities. They concluded that when the test is adequately prepared, there are no problems to students with learning disabilities

According to the authors, PrT developed by e-mail together with a cycle of reviews with the materials of study seems to be an important tool to use for improving gain of knowledge

The PrT application in computed-based format was well accepted by the students.

The use of fixed absolute standards in progress tests developed in a norm referenced setting is precarious because of the variations in difficulty of different tests. The authors recommend: constructing a test by selecting items from a bank of items of known difficulty, which enables measurement and control of the test difficulty, or 2) a more expressive standard setting procedure which is based on item judgment by a panel of experts

Graduated students as judges are a useful method for development of a progress test. However, viability was a problem detected in the search

The authors explain the approach to produce highest possible quality items for progress test.

The use of a panel of writers as judges is not feasible to obtain a reliable passing score. The established passing score seems less credible. The political acceptability of a panel from recently graduated students seems doubtful. A better standard can be obtained from a mixed panel (item writers and graduates)

The findings support the feasibility of using the method of average cumulative deviation. This method compares schools' performance on student knowledge, reveal the impact of curricular changes on knowledge gain, and diagnose strengths and weaknesses of current or developing curricula

This study showed that the development of standards for the PrT represents a challenge. Authors demonstrated that successive evaluation of students' performance can produce a rich source of information. This action helps set standards setting for PrT

Equating is a statistical process that controls differences in the difficulty among forms, so that, the scores can be used interchangeably. PrT must produce a true assessment of what you want to measure. Authors discuss a usage of a hybrid equating design as a potential solution for development of the PrT

The blueprint covers questions on the curriculum and gives possibilities to monitoring the quality of test. Associated to this fact, the PrT can provide a very important source of feedback to learners. 
Table 1. Cont'd.

To investigate the use of PrT in clinical education through growth of knowledge and impact of recent training (De Champlain et al., 2010)

To analyze the use of procedure for cross-institutional benchmarking between institutions which use PrT (Schauber and Nouns, 2010)

To analyze the reliability and credibility of several panels of judgement to PrT (Anderson et al., 2011).

To investigate a Bayesian statistical approach used for reducing error in PrT (Ricketts and Moyeed, 2011)
The study helps to show the importance of equated scores because of its capacity in promoting an assessment of growth without the confounding effects; and because it explains the mechanism how clinical knowledge grows

Cross-institutional comparisons can be made using the cumulative deviation method. The model seeks to interpret standards and clarify the differences of the data obtained in the PrT. Nevertheless, the method has limitations, for example, it does not discriminate partly depending on the structure of the data

This study found out that identifying the best judges for standard setting is paramount to successful implementation of a progress test. Alumni and mixed faculty-alumni judge panels had difficulty producing credible student outcomes. Judge panels should be preferred when established progress test criteria.

The statistical approach from this study produced a best estimate of scores and smaller standard error of values. The simplicity of the method facilitates its use along the large cohorts of students and frequent tests

\section{PrT used in collaboration}

To report the progress test and its convenience for crossinstitutional cooperation (Vleuten et al., 2004)

To evaluate the potential of international sharing of PrT (Verhoeven et al., 2005).

To investigate whether there is discrimination between items of PrT used for inter-curriculum comparison (Muijtjens et al., 2007).

To detail various stages of $\operatorname{PrT}$ development in collaboration to the National Board of Medical Examiners (NBME) (Swanson et al., 2010).

To describe collaborative banks with questions for PrT, methods used to validate and adapt questions and to make comparisons among questions from different sources (Freeman et al., 2010).
The economic benefit is one of the advantages of sharing materials among schools. This allows a construction of the PrT with more quality. Sharing achievement contributes to educational quality

The PrT is an important methodology to evaluate medical schools. Evidences show that sharing test material saves resources and seems to be a viable strategy

The researcher found that it may not be appropriate to make comparisons between results on identical tests from students of different schools when tests are composed by staff of one of the schools only. The authors concluded that the source of the bias items has a propensity to compromise the reliability and fairness of comparison. The solution to this problem must involve the provision of equal number of items by the schools. Another proposal is to make a more rigorous review

This work shows that it is feasible to develop the PrT in the UK on taken items from the United States Medical Licensing Examination (USMLE). The use of the same blueprint helps to improve the comparison over time. Furthermore, the use of multiple test forms and involving experts are also important considerations. The authors recommend caution when using materials from other countries due to cultural characteristics, laboratory units, terminologies, care protocols and drug formularies

This work shows that transferring questions from one institution to another is not a simple task. There are issues related to curricular and cultural differences. The effective use of questions from external banks needs an amount of work to adapt them to local conditions 
Table 1. Cont'd.

To report advantages and disadvantages of the collaboration in PrT (Schuwirth et al., 2010)
The authors consider that collaboration in Netherlands in context of PrT is adequate, but there is some riskiness. The main advantages are: the possibilities for curricular comparisons, opportunities for conducting research, cost reduction and reach of many students by application of PrT. Some disadvantages are: conceptual differences about what items are good quality and regulatory issues of each institution.
Instrument to Comparison (between curricula, methods of learning...)

To compare the academic performance of two medical schools with two different learning method (Verhoeven et al., 1998)

To compare scores on knowledge of two cohorts of students from two curricula (old and new) in their final year (Peeraer et al., 2009)

To compare behavior of students between two curricula (Van Der Veken et al., 2009).

To compare the increase of knowledge among students of a new and another long-established school using the PrT (Finucane et al., 2010)

To study methods for educational evaluation between schools (Muijtjens et al., 2008b).

To evaluate the results of a competency-based active learning curriculum (CBAL) compared to the existing active learning curriculum (AL) (Kerdijk et al., 2013)

To confront the influence of PBL and lecture-based learning (LBL) to the learning development of students (Sangestani et al., 2013)

To measure knowledge retention in schools with PBL curriculum and traditional curriculum (Heijne-Penninga et al., 2013)

To describe the progress of the clinical reasoning skills using PrT results (Postma et al., 2015).
PrT was used to comparison between two curricula. There were no significant differences in cognitive performance for curricula.

This study evaluated the effect of curriculum change from a medical school. PrT was used as instrument to measure scores. No significant differences were found between two curricula (old and new)

PrT was used to measure the learning between integrated medical curriculum (ICMC) and conventional medical curriculum (CMC). The differences obtained in ICMC medical students were attributed to the stronger emphasis on clinically relevant basic sciences in the first years and to the stronger integration of basic and clinical sciences in the ICMC.

The level of knowledge acquisition is similar between these groups of students. There is feasibility in inter-institutional and international collaboration in PrT. This type of collaboration can be offered as a useful quality assurance tool.

The study shows that single-point benchmarking, among three schools that used PrT produces questionable results. For the other hand, the better method seems to be benchmarking based on longitudinal data and cumulative deviations

Based on PrT results, this research could not prove that competency-based education is better than traditional form for students. Authors recommend further studies

Results of PrT showed that students in PBL group experiments more rapid progress of learning than the other lecture-based

PrT was used as an assessing method to evaluate performance of students in three medical schools. PBL curriculum is better than the traditional curriculum. The use of closed and open-book tests contribute to the long-term knowledge retention

PrT was used to compare case-based learning against lecturebased teaching. Case-based learning seems to contribute to accurate clinical decisions more than lecture-based teaching.

al., 2003; Rodrigues and Catarina, 2007; Löwe et al., 2008; Dijksterhuis et al., 2009; Ravesloot et al., 2012).

\footnotetext{
The authors have discussed aspects of the practice of
}

2015; Ali et al., 2015). Development of PrT in postgraduation training seems possible, but in this revision showed that there is a need for further studies (Kramer et 
PrT as the type of questions, reference criteria, use of internet-based tools and costs (Vleuten et al., 1996; McHarg et al., 2005; Rademakers et al., 2005; Muijtjens et al., 2010; Ricketts et al., 2010; Rickets et al., 2010b; Kerfoot et al., 2011; Karay et al., 2012).

Several articles present procedures for the achievement of standards for the PrT. Statistical methods, bank of items, better judges for the questions and quality of test are discussed (Verhoeven et al., 1999b; Muijtjens et al., 1998; Muijtjens et al., 2008b; Ricketts and Moyeed, 2011; Anderson et al., 2011; De Champlain et al., 2010; Langer and Swanson, 2010). Despite this development of standards for the PrT represents a challenge (Rickets et al., 2009).

Collaborative studies about PrT show mainly the economic benefit (Vleuten et al., 2004; Verhoeven et al., 2005). The PrT can be used for comparison purposes, but there are existing error sources that need to be considered (Swanson et al., 2010; Muijtjens et al., 2007; Freeman et al., 2010; Schuwirth et al., 2010).

For comparison purposes, PrT has several features. The studies show that PrT can be used for comparing types of curricula such as problem based versus traditional learning (Verhoeven et al., 1998; Nouns et al., 2012), problem versus lecture based learning (Sangestani et al., 2013), to evaluate effectiveness of curriculum change (Peeraer et al., 2009); to measure transition of a conventional to an integrated contextual medical curriculum (Van Der Veken et al., 2009), infer performance results among students from different schools (Muijtjens et al., 2007), and comparison of curricula (Muijtjens et al., 2008; Muijtjens et al., 2008b).

Although most studies have been conducted in developed countries, PrT has been applied in countries with few resources (Aarts et al., 2010; Mardiastuti and Werdhani, 2011). Some experiences involving the PrT has been carried out in Brazil, that is a developing country. Studies about application of PrT in Brazilian medicine schools (Tomic et al., 2005; Sakai et al., 2011) demonstrate the possibility of implementation and execution of it.

The use of continuous assessment has emerged as a proposal to improve student learning and develop educational programs in Pharmacy Schools (Plaza, 2007; Szilagyi, 2008; Begley et al., 2013). The Accreditation Council for Pharmacy Education recommends that pharmacy schools can use evaluations that can achieve desired educational objectives. In this context, progress test has been used as both formative assessment as summative (Duncan-Hewitt et al., 2007; Szilagyi, 2008; Anderson Jr and Nelson, 2011; UCL, 2014; Karimi et al., 2014).

The Pharmacy courses in Brazil are guided by a national curriculum guideline (Brazil, 2002). This guideline establishes the profile for formation of the pharmacist. Several institutions have discussed the improvement of the teaching of pharmacy in Brazil (ABERFABIO, 2013).
Despite these efforts, the pharmaceutical education still has been very influenced by memorization and repetition of content often disconnected from the reality. In addition, the absence of methodologies like problem based learning left a void for critical and reflexive constructions in the learning process (Almeida et al., 2014; Blouin et al., 2008).

The last Pan American Conference on Pharmaceutical Education in 2014 defended the adoption of a competency-based curriculum. Knowledge is an important cognitive component needed to develop competencies (OPAS, 2014). The PrT is a tool to assess knowledge and can fill this need. Pharmacy schools can adapt the PrT to provide assessment that measure the final objectives of their curricula and start an era of evaluation that guides learning and contributes to the quality of education.

\section{Conclusion}

There is much evidence about the use of the PrT as an evaluation method to enhace learning in graduation and even pos-graduation. The literature also records studies which seek to qualify the design and implementation of the PrT, presenting proposals for standards, common practices, experiences in collaboration and showing features of the PrT used as comparison tool between types of curricula, learning methods etc. Although most studies describe experiences in medical schools, there are descriptions of the application of the test in other courses in the health area. It was not detected in this review study the use of this test in pharmacy schools. However, we advocate that the PrT can be used by the schools of pharmacy in the same way as is already the case in other courses.

\section{Conflicts of Interests}

The authors have not declared any conflict of interests.

\section{REFERENCES}

Aarts R, Steidel K, Manuel BAF, Driessen EW (2010). Progress testing in resource-poor countries: a case from Mozambique. Med. Teach. 32(6):461-463.

Al-Alwan I, Al-Moamary M, Al-Attas N, Al-Kushi A, Al-Banyan E, Zamakhshary M, Al Kadri HMF, Tamim H, Magzoub M, Hajeer A, Schmidt $H$ (2011). The progress test as a diagnostic tool for a new PBL curriculum. Educ. Health 24(3):493.

Albano MG, Cavallo F, Hoogenboom R, Magni F, Majoor G, Manenti F, Schuwirth L, Stiegler I, Vleuten ECVD (1996). An international comparison of knowledge levels of medical students: The Maastricht Progress Test. Med. Educ. 30(4):239-245.

Ali K, Coombes L, Kay E, Tredwin C, Jones G, Ricketts C, Bennett J (2015). Progress testing in undergraduate dental education: The Peninsula experience and future opportunities. Eur. J. Dent. Educ. (4):1-6.

Anderson HG Jr, Nelson AA (2011). Reliability and Credibility of Progress Test Criteria Developed by Alumni, Faculty, and Mixed Alumni-Faculty Judge Panels. Am. J. Pharm. Educ. 75(10):1-9. 
Basu S, Roberts C, Newble DI, Snaith M. Competence in the musculoskeletal system: assessing the progression of knowledge through an undergraduate medical course (2004). Med. Educ. 38(12):1253-1260.

Bennett J, Freeman A, Coombes L, Kay L, Ricketts C (2010). Adaptation of medical progress testing to a dental setting. Med. Teach. 32(6):500-502.

Begley K, Monaghan Ms, Qi Y (2013). Repeated testing to improve skills in a pharmacy practice laboratory course. Am. J. Pharm. Educ.77(6):1-6.

Berkel V, Henk JM, Herman JPN, Geerligs T (1994). The influence of progress tests and block tests on study behaviour. Instr. Sci. 22(4):317-333.

Blake JM, Norman GR, Keane DR, Mueller CB, Cunnington J, Didyk N (1996). Introducing progress testing in McMaster University's problem-based medical curriculum: psychometric properties and effect on learning. Acad. Med. 9:1002-1007.

Boshuizen HP, Van der Vleuten CP, Schmidt HG, Machiels-Bongaerts $M$ (1997). Measuring knowledge and clinical reasoning skills in a problem-based curriculum. Med. Educ. 31(2):115-121.

BRAZIL (2002). National Council of Education. Superior Education Chamber. Resolution CNE/CES number 19/02/2002. Avaliable in url: portal.mec.gov.br/cne/arquivos/pdf/CES022002.pdf

Chen Y, Henning M, Yielder J, Jones R, Wearn A, Weller J (2015). Progress testing in the medical curriculum : students ' approaches to learning and perceived stress. BMC Med. Educ. 15(1):147.

Cohen-Schotanus J, Schönrock-Adema J, Bouwkamp-Timmer T, Van Scheltinga GRT, Kuks JBM (2008). One-year transitional programme increases knowledge to level sufficient for entry into the fourth year of the medical curriculum. Med. Teach. 30(1):62-66.

Coombes L, Ricketts C, Freeman A, Stratford J (2010). Beyond assessment: feedback for individuals and institutions based on the progress test. Med. Teach. 32:486-490.

De Champlain AF, Cuddy MM, Scoles PV, Brown M, Swanson DB, Holtzman K, Buttler G (2010). Progress testing in clinical science education: results of a pilot project between the National Board of Medical Examiners and a US Medical School. Med. Teach. 32(6):503-508.

de Koning BB, Loyens SMM, Rikers RMJP, Smeets G, van der Molen HT (2012). Generation Psy: Student characteristics and academic achievement in a three-year problem-based learning bachelor program. Learn. Individ. Differ. 22(3):313-323.

Dijcks R, Prince KJ, Vleuten CPMV, Scherpbier AJJA (2003). Validity of objective tests towards peer-rated competence by students. Med. Teach. 25(3):273-276.

Dijksterhuis MGK, Scheele F, Schuwirth LWT, Essed GGM, Nijhuis JG, Braat DDM (2009). Progress testing in postgraduate medical education. Med. Teach. 31(10):464-468.

Dornan T, Scherpbier A, Boshuizen H (2003). Towards valid measures of self-directed clinical learning. Med. Educ. 37:983-991.

Duncan-Hewitt W, Jungnickel P, Evans RL (2007). Development of an Office of Teaching, Learning and Assessment in a Pharmacy School. Am. J. Pharm. Educ. 71(2):1-8.

Finucane P, Flannery D, Keane D, Norman G (2010). Cross-institutional progress testing: Feasibility and value to a new medical school. Med. Educ. 44:184-186.

Freeman A, Nicholls A, Ricketts C, Coombes L (2010). Can we share questions? Performance of questions from different question banks in a single medical school. Med. Teach. 32(6):464-466.

Freeman A, Van Der Vleuten C, Nouns Z, Ricketts C (2010). Progress testing internationally. Med. Teach. 32(6):451-455.

Freeman AC, Ricketts C (2010). Choosing and designing knowledge assessments: experience at a new medical school. Med. Teach. 32(7):578-81.

Gold J, DeMuth R, Mavis B, Wagner D (2015). Progress testing 2.0: clinical skills meets necessary Science. Med. Educ. Online 20:1-4.

Heijne-Penninga M, Kuks JBM, Hofman WHA, Muijtjens AMM, CohenSchotanus J (2013). Influence of PBL with open-book tests on knowledge retention measured with progress tests. Adv. Health Sci. Educ. 18(3):485-495.

Hurk VD, Marianne M, Wolfhagen IH, Dolmans DH (1999). The impact of student-generated learning issues on individual study time and academic achievement. Med. Educ. 33(11):808-814.

Johnson TR, Khalil MK, Peppler RD, Davey DD, Kibble JD (2014). Use of the NBME Comprehensive Basic Science Examination as a progress test in the preclerkship curriculum of a new medical school. Adv. Physiol. Educ. 38(4):315-320.

Karay Y, Schauber SK, Stosch C, Schuettpelz-Brauns K (2012). Can computer-based assessment enhance the acceptance of formative multiple choice exams? A utility analysis. Med. Teach. 34(4):292-296.

Karimi R, Meyer D, Fujisaki B, Stein S (2014). Implementation of an Integrated Longitudinal Curricular Activity for Graduating Pharmacy Students. Am. J. Pharm. Educ. 78(6):1-8.

Kerdijk W, Snoek JW, Van HEA, Cohen-schotanus J (2013). The effect of implementing undergraduate competency-based medical education on students' knowledge acquisition, clinical performance and perceived preparedness for practice: a comparative study. BMC Med. Educ. 13:1-10.

Kerfoot BP, Shaffer K, McMahon GT, Baker H, Kirdar J, Kanter S, Corbett EC, Berkow R, Krupat E, Armstrong EG (2011). Online "Spaced Education Progress-Testing" of Students to Confront Two Upcoming Challenges to Medical Schools. Acad. Med. 86(3):300306.

Kramer AWM, Düsman H, Tan LHC, Jansen KJM, Grol RPTM, van der Vleuten CP (2003). Effect of extension of postgraduate training in general practice on the acquisition of knowledge of trainees. Fam. Pract. 20(2):207-212.

Langer MM, Swanson DB (2010). Practical considerations in equating progress tests. Med. Teach. 32:509-512.

Löwe B, Hartmann M, Wild B, Nikendei C, Kroenke K, Niehoff D, Henningsen P, Zipfel S, Herzog W (2008). Effectiveness of a 1-year resident training program in clinical research: A controlled beforeand-after study. J. Gen. Intern. Med. 23(2):122-128.

Mardiastuti HW, Werdhani RA (2011). Grade point average, progress test, and try out's test as tools for curriculum evaluation and graduates' performance prediction at the national board examination. J. Med. Med. Sci. 2(12):1302-1305.

McHarg J, Bradley P, Chamberlain S, Ricketts C, Searle J, McLachlan JC (2005). Assessment of progress tests. Med. Educ. 39(2):221-227.

Muijtjens AMM, Hoogenboom RJI, Verwijnen GM, Van Der Vleuten CPM (1998). Relative or Absolute Standards in Assessing Medical Knowledge Using Progress Tests. Adv. Health Sci. Educ. Theory Pract. 3(2):81-7.

Muijtjens AMM, Schuwirth LWT, Cohen-Schotanus J, Thoben AJNM, Vleuten CPMVD (2008b). Benchmarking by cross-institutional comparison of student achievement in a progress test. Med. Educ. 42(1):82-88.

Muijtjens AMM, Schuwirth LWT, Cohen-Schotanus J, Van Der Vleuten CPM (2007). Origin bias of test items compromises the validity and fairness of curriculum comparisons. Med. Educ. 41(12):1217-1223.

Muijtjens AMM, Schuwirth LWT, Cohen-Schotanus J, Van Der Vleuten CPM (2008). Differences in knowledge development exposed by multi-curricular progress test data. Adv. Health Sci. Educ. 13(5):593605. Muiitjens AMM, Timmermans I, Donkers J, Peperkamp R, Medema H, Cohen-Schotanus J, Thoben A, Wenink ACG, van der Vleuten CPM (2010). Flexible electronic feedback using the virtues of progress testing. Med. Teach. 32:491-495.

Norman G, Neville A, Blake JM, Mueller B (2010). Assessment steers learning down the right road: impact of progress testing on licensing examination performance. Med. Teach. 32:496-499.

Nouns Z, Schauber S, Witt C, Kingreen H, Schu“ttpelz-Brauns K (2012). Development of knowledge in basic sciences: A comparison of two medical curricula. Med. Educ. 46(12):1206-1214.

Nouns ZM, Georg W (2010). Progress testing in German speaking countries. Med. Teach. 32:467-470.

O'Neill PA (2000). The role of basic sciences in a problem-based learning clinical curriculum. Med. Educ. 34(8):608-613.

Ogaji IJ, Kahiga TM, Gachuno OW, Mwangi JW (2016). Development of Pharmacy Education in Kenya Universities to date. Afr. J. Pharm. Pharm. 10(18):385-392.

OPAS. Organización Panamericana de la Salud. Pan American Conference on Pharmaceutical Education. (2014). Evaluable on: http://www.paho.org/hq/index.php?option=com_content\&view=article \&id $=8374 \% 3$ A2013-pharmaceutical- 
education\&catid $=4831 \% 3$ Apharmaceuticaleducation\&ltemid=39720\&lang=pt. Acess in 08/28/2016.

Peeraer G, De Winter BY, Muijtjens AMM, Remmen R, Bossaert L, Scherpbier AJJA (2009). Evaluating the effectiveness of curriculum change. Is there a difference between graduating student outcomes from two different curricula? Med. Teach. 31(3):64-68.

Plaza CM (2007). Progress Examinations in Pharmacy Education. Am. J. Pharm. Educ. 71(4):1-7.

Postma TC, White JG (2015). Developing integrated clinical reasoning competencies in dental students using scaffolded case-based learning - empirical evidence. Eur. J. Dent. Educ. 27:1-9.

Rademakers J, Ten Cate TJ, Bär PR (2005). Progress testing with short answer questions. Med. Teach. 27(7):578-582.

Ravesloot C, van der Schaaf M, Haaring C, Kruitwagen C, Beek E, Ten Cate O, Schaik JV (2012). Construct validation of progress testing to measure knowledge and visual skills in radiology. Med. Teach. 34(12):1047-1055.

Ricketts C, Brice J, Coombes L. (2010b). Are multiple choice tests fair to medical students with specific learning disabilities? Adv. Health Sci. Educ. 15(2):265-275.

Ricketts C, Freeman A, Pagliuca G, Coombes L, Archer J (2010). Difficult decisions for progress testing: how much and how often? Med. Teach. 32(6): 513-515.

Ricketts C, Freeman AC, Coombes LR (2009). Standard setting for progress tests: Combining external and internal standards. Med. Educ. 43:589-593.

Ricketts C, Moyeed R (2011). Improving progress test score estimation using Bayesian statistics. Med. Educ. 45(6):570-577.

Rodrigues G, Catarina S (2007). The Relationship of Learning Environment, Quality of Life and Study Strategies Measures to Anesthesiology. Econ. Educ. Pol. 104(6):1467-1472.

Sakai MH, Ferreira Filho OF, Matsuo T (2011). Avaliação do crescimento cognitivo do estudante de medicina: aplicação do teste de equalização no teste de progresso. Rev. Bras. Educ. Med. 35(4):493-501.

Sangestani G, Khatiban M (2013). Comparison of problem-based learning and lecture-based learning in midwifery. Nurse Educ. Tod. 33(8):791-795. Schaap L, Schmidt HG, Verkoeijen PPJL (2012). Assessing knowledge growth in a psychology curriculum: which students improve most? Assess. Eval. High. Educ. 37(7):875-887.

Schauber S, Nouns ZM (2010). Using the cumulative deviation method for cross-institutional benchmarking in the Berlin progress test. Med. Teach. 32(6):471-475.

Schauber SK, Hecht M, Nouns ZM, Kuhlmey A, Dettmer S (2015). The role of environmental and individual characteristics in the development of student achievement: a comparison between a traditional and a problem-based-learning. Adv. Health Sci. Educ. 20(4):1033-1052.

Schuwirth L, Bosman G, Henning RH, Rinkel R, Wenink ACG (2010). Collaboration on progress testing in medical schools in the Netherlands. Med. Teach. 32:476-479.

Szilagyi JE (2008). Curricular Progress Assessments: The MileMarker. Am. J. Pharm. Educ. 72(5):1-4.

Swanson DB, Holtzman KZ, Butler A, Langer MM, Nelson MV, Chow JWM, et al (2010). Collaboration across the pond: the multi-school progress testing project. Med. Teach. 32:480-485.

Tomic ER, Martins MA, Lotufo PA, Benseñor IM (2005). Progress testing: evaluation of four years of application in the school of medicine, University of São Paulo. Clinics 60(5):389-396.

UCL School of Pharmacy (2014). Joint Programs Board London. Postgraduate Diploma in General Pharmacy Practice. Programme Handbook. 33p.

Van Der Veken J, Valcke M, De Maeseneer J, Schuwirth L, Derese A (2009). Impact on knowledge acquisition of the transition from a conventional to an integrated contextual medical curriculum. Med. Educ. 43(7):704-713 van der Vleuten CPM, Schuwirth LWT, Muijtjens AMM, Thoben AJNM, Cohen-Schotanus J, van Boven CP (2004). Cross institutional collaboration in assessment: a case on progress testing. Med. Teach. 26(8):719-725.

van der Vleuten CPM, Verwijnen GM, Wijnen WHFW (1996). Fifteen years of experience with progress testing in a problem-based learning curriculum. Med. Teach. 18(2):103-109.

van Diest $R$, van Dalen J, Bak M, Schruers K, van der Vleuten C, Muijtjens AMM, Scherpbier A (2004). Growth of knowledge in psychiatry and behavioural sciences in a problem-based learning curriculum. Med. Educ. 38(12):1295-1301.

Vantini I, Benini L (2008). Models of learning, training and progress evaluation of medical students. Clin. Chim. Acta. 393(1):130-16.

Verhoeven BH, Scherpbier AJJA, Ldrinet RSGHO, Oeseburg B, Bulte JA (1998). An analysis of progress test results of PBL and non-PBL students. Med. Teach. 20(4):310-316.

Verhoeven BH, Snellen-Balendong HAM, Hay IT, Boon JM, van der Linde MJ, Blitz-Lindeque JJ, Hongenboom RJI, Verwijnen GM, Wijnen WHFW, Scherpbier AJJA, van der Vleuten CPM (2005). The versatility of progress testing assessed in an international context: a start for benchmarking global standardization? Med. Teach. 27(6):514-520.

Verhoeven BH, van der Steeg AFW, Scherpbier AJJA, Muijtjens AMM, Verwijnen GM, van der Vleuten CPM (1999). Reliability and credibility of an Angoff standard setting procedure in progress testing using recent graduates as judges. Med. Educ. 33:832-837.

Verhoeven BH, Verijnen GM, Scherpbier AJJA, Schuwirth LWT, Van der Vleuten CPM (1999). Quality assurance in test construction: the approach of a multidisciplinary central test committee. Educ. Health. 12(1):49-60.

Verhoeven BH, Verwijnen GM, Muijtjens AMM, Scherpbier AJJA, Van Der Vleuten CPM (2002). Panel expertise for an Angoff standard setting procedure in progress testing: Item writers compared to recently graduated students. Med. Educ. 36(9):860-867.

Verhoeven BH, Verwijnen GM, Scherpbier AJJA, van der Vleuten CPM (2002). Growth of medical knowledge. Med. Educ. 36(8):711-717.

Wade L, Harrison C, Hollands J, Mattick K, Ricketts C, Wass V (2012). Student perceptions of the progress test in two settings and the imlications for test deployment. Adv. Health Sci. Educ. 17:573-583. 